\title{
Colonization of Methicillin-resistant Staphylococcus aureus (MRSA) and History of Hospitalization: how strong do they correlate in ICU Patients?
}

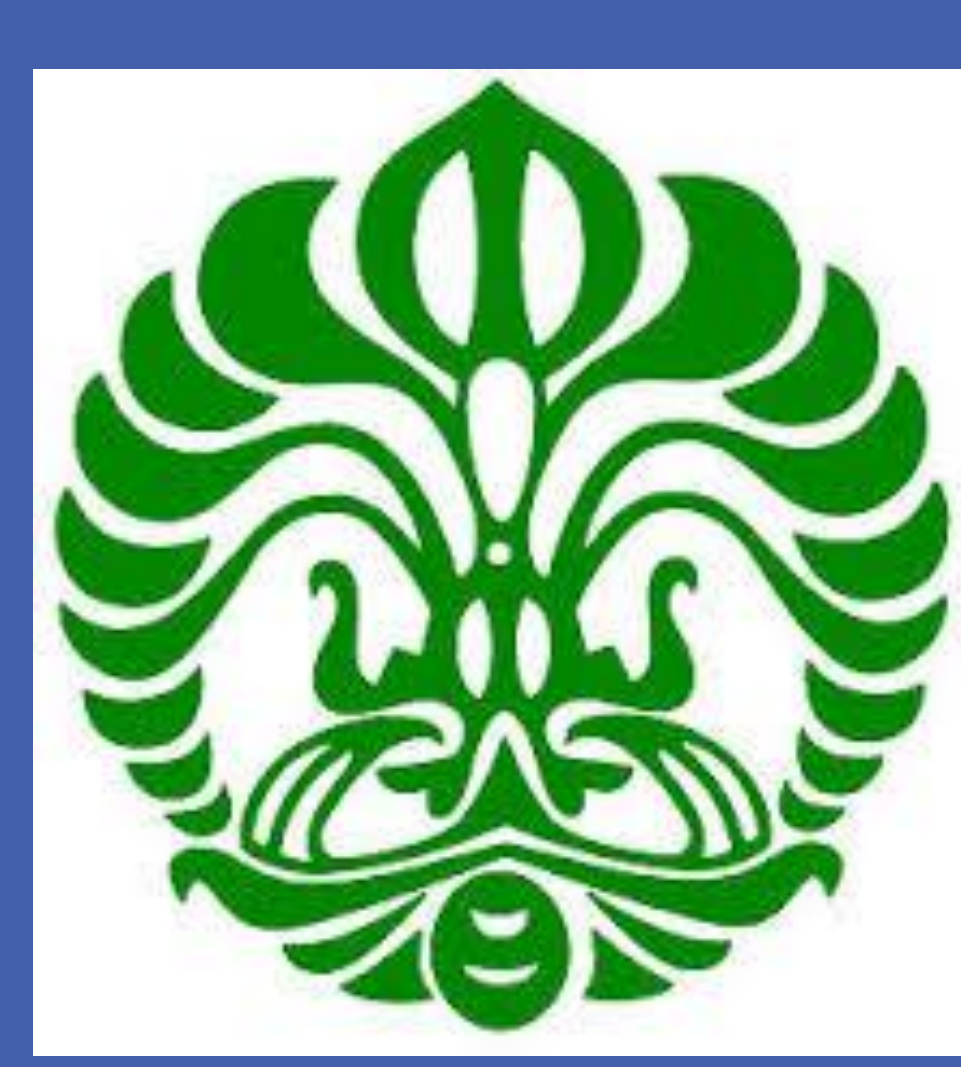

\author{
B. Amalia, YR. Saharman
}

Department of Clinical Microbiology, Faculty of Medicine, Universitas Indonesia

\section{INTRODUCTION}

Methicillin-resistant Staphylococcus aureus (MRSA) is one of the Multidrug-resistant organisms (MDRO) which has been quite an endemic in many healthcare facilities, especially in the Intensive Care Unite (ICU) of hospitals. ${ }^{1}$ History of patients' hospitalization before ICU admission has been considered to be one of the risk factors for MRSA colonization in patients. Problems arised after knowing that ICU patients with MRSA colonization are at high risk of MRSA infection. ${ }^{2}$

Every year, MRSA prevalence in Indonesia showed significant progressivity. In 1986 the MRSA prevalence is $2,5 \%$, then raised to $9,4 \%$ in 1993 . In 2006 , it went farther to $23,5 \%$. In 2008, a survey conducted in $\mathrm{dr}$. Soetomo Hospital implied there were $34,92 \%$ MRSA in wound specimens. ${ }^{3}$

Therefore, we require data of MRSA colonization associated history of patients' hospitalization before ICU admission in hopes that the incidence of MRSA colonization in Indonesia hospitals can be reduced.

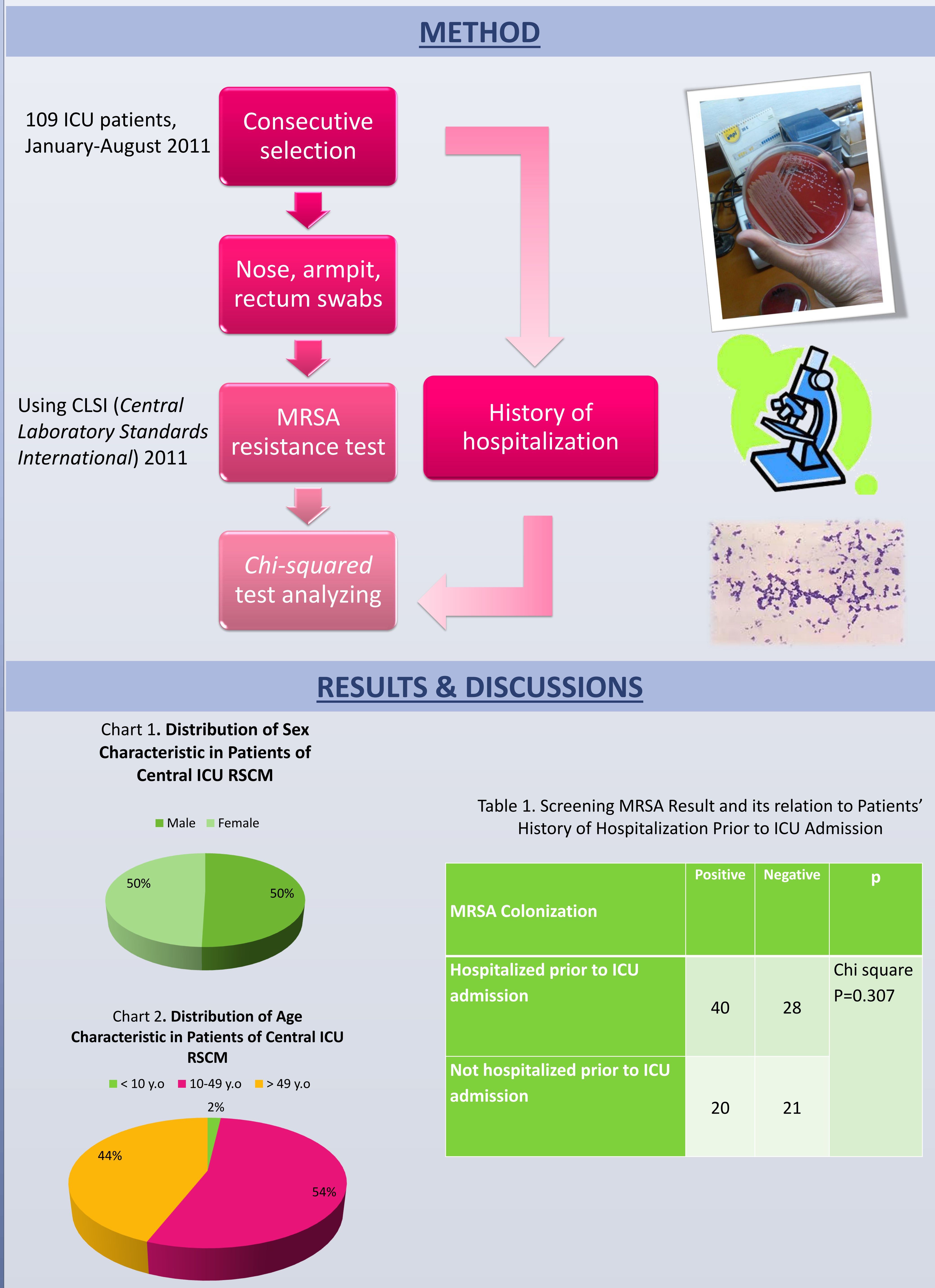

In this study, samples were dominantly male sex $(50,4 \%)$ and $10-49$ years old $(54,1 \%)$. The number of patients who had been hospitalized prior to ICU admission in RSCM was more than those who had been not, it was 68 of 109 patients $(62,4 \%)$. The proportion of patients with positive MRSA colonization and had been hospitalized before admission to the ICU was higher than those who had been not (58.8\% vs. $48.8 \%)$.

In patients who have had history of hospitalization, there was positive MRSA colonization 1.2 times higher than those who haven't had. $(C I 95 \%-3,087 ; 5,499)$, $P=$ 0,307 . This result was obtained because there were quite plentiful risk factors of MRSA colonization, particularly in patients who entered the ICU setting (history of antibiotic use and contact with MRSA infected of carrier individuals ${ }^{4}$ )

Patients who were administered to ICU, not only got potentially harmful MRSA colonization from the healthcare facilities where they had been treated before, but also from community where they lived. ${ }^{5}$ It indicates that MRSA threatened not only patients with history of hospitalization, but also those who had been not hospitalized.

\section{RESULTS \& DISCUSSIONS}

Chart 3. MRSA Colonization Test Result ( $\mathrm{n}=109)$
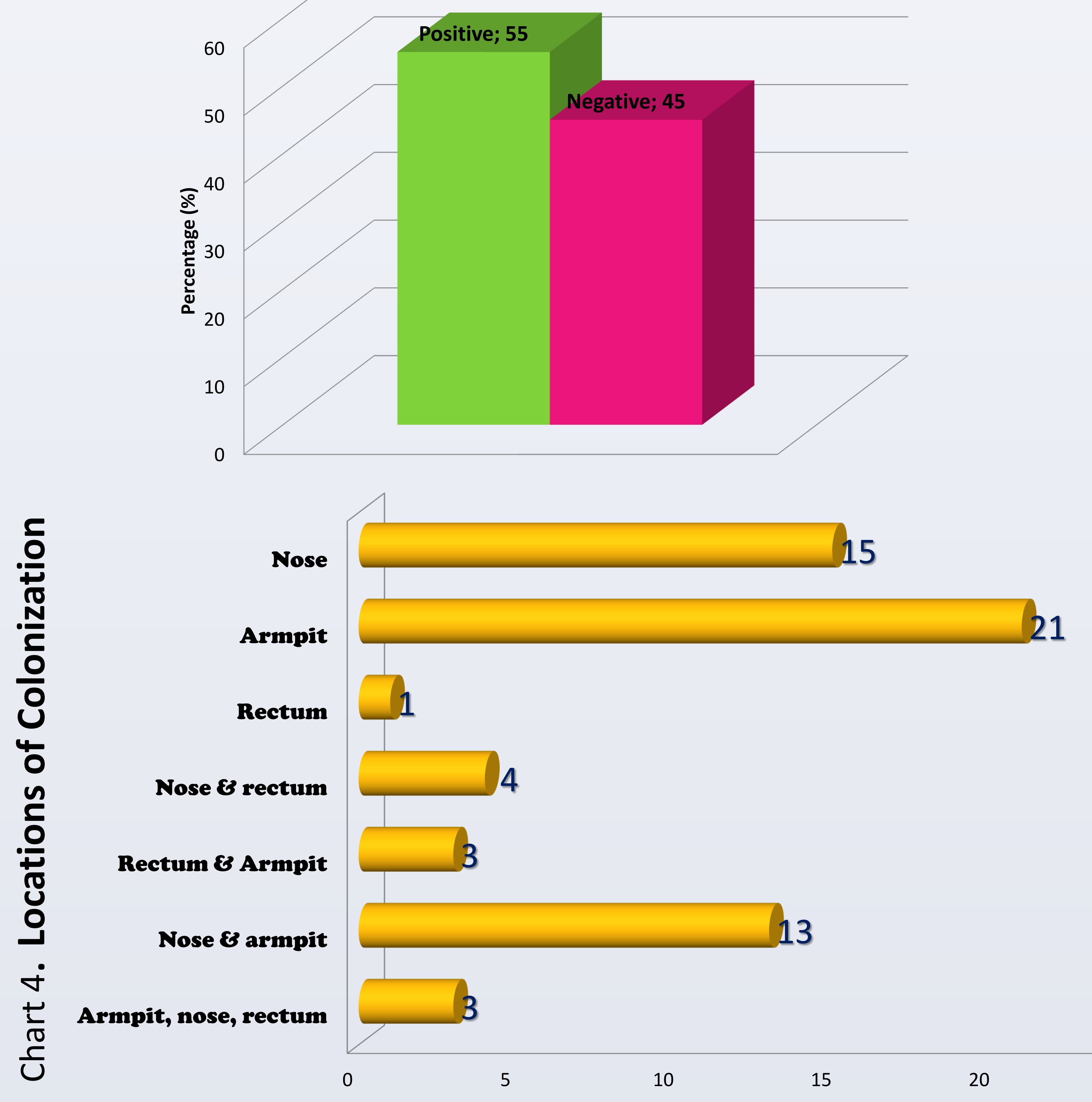

There were more patients colonized by MRSA in ICU (55\%) than those who weren't. The high number of potential reservoirs in ICU for MRSA has enhanced its colonization, they were patients, medical devices, and healthcare personnels. ${ }^{4}$

The colonization locations were armpit (21 patients), nose (15 patients), and rectum (1 patient). There were 13 patients who had MRSA colonization in nose and armpit at the same time. Nose and armpit were remain the favored site for MRSA colonization. It was in line with the fact that Community MRSA (c-MRSA) transmission was by skin-to-skin or skinto-device contact.

\section{CONCLUSIONS}

MRSA colonization prevalence in patients of Central ICU RSCM in 2011 was $55 \%$.

* The most favored site of MRSA colonization were armpit and nose.

* There was no significant statistic relationship between MRSA colonization and the history of patients' hospitalization before ICU admission which suggests colonization also exist in * Indonesia hospitals should community.

\section{RECOMMENDATIONS}

Hospitals should undergo MRSA screening in all of patients admissions.

* MRSA genotyping test in patients with MRSA colonization should be considered, since it is an important procedure to determine the strain of MRSA. (CA-MRSA or HA-MRSA) implement comprehensive MRSA prevention and control program.

\section{REFERENCES}

Fu-Der Wang et al. Risk factors and mortality of nosocomial infections of methicillin-resistant Staphylococcus aureus in an intensive care unit. Journal of Critical Care Elsevie; 2011. p. 83-84. intensive care unit. Journal of Critical Care Elsevie; 2011. p. 83-84. hospitalization is the major risk factor. JSTOR; 2000 . p. $726-727$. rescription in hospital. CMI. 2001; 7: p. 12

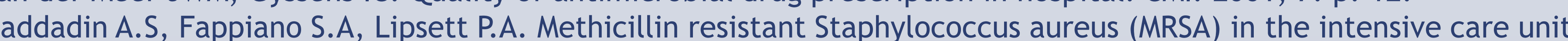
Baltimore: Postgraduate Medical Jurnal; Jul 2002. 78, 921. p. 385-392 Yang ES, Tan J, Rieg G, et al. Body site colonization prevalence in patients with community-associated methicillin resistan Staphylococcus aureus infections [abstract 285]. In: Program and Abstracts of the 45th Annual Meeting of the Infectious Diseases Society of America (San Diego). Alexandria, VA: Infectious Diseases Society of America, 2007:107.

\section{ACKNOWLEDGEMENTS \& CONTACT}

Thank you to my supervisor Yulia Rosa, my loyal research team Arini, Putra, Arcci, Keiko, Avy and my school Faculty of Medicine University of Indonesia for funding my participation in this event.

Email: beladenta@yahoo.com/ phone: +628569960838 